\title{
Survival of Tilletia indica Teliospores in Different Soils
}

\author{
M. R. Bonde, D. K. Berner, S. E. Nester, and G. L. Peterson, USDA-ARS, Foreign Disease-Weed Science Re- \\ search Unit, Fort Detrick, MD 21702-5023; M. W. Olsen, Department of Plant Pathology, University of Arizona, \\ P.O. Box 210036, Tucson 85721-0036; B. M. Cunfer, University of Georgia, Griffin 30223-1797; and T. Sim, Kan- \\ sas Department of Agriculture, Topeka 66619-0282
}

\begin{abstract}
Bonde, M. R., Berner, D. K., Nester, S. E., Peterson, G. L., Olsen, M. W., Cunfer, B. M., and Sim, T. 2004. Survival of Tilletia indica teliospores in different soils. Plant Dis. 88:316-324.

To determine the potential for Tilletia indica, cause of Karnal bunt of wheat, to survive and become established in new areas, a teliospore longevity study was initiated in Kansas, Maryland, Georgia, and Arizona. Soil from each location was infested with $T$. indica teliospores and placed in polyester mesh bags. The bags were placed within soil from the same location within polyvinyl chloride pipes. Pipes were buried in the respective plots such that the bags were at 5-, 10-, and $25-\mathrm{cm}$ depths. Each pipe was open at the ends to allow interaction with the outside environment, however fitted with screens preventing possibility of teliospore escape. In the Karnal bunt-quarantine area of Arizona, bags of infested soil also were placed outside the pipes. Teliospore-infested soil from each location was maintained dry in a laboratory. During the first 2 years, viability declined more rapidly in pipes than outside pipes, and more rapidly in fields in Kansas and Maryland than in Georgia or Arizona. After 2 years, viability declined nearly equally. In the laboratory over 3 years, viability decreased significantly more rapidly in dry soil from Kansas or Maryland than in dry soil from Georgia or Arizona, while pure teliospores remained unchanged. We hypothesized that soils, irrespective of weather, affect teliospore longevity.
\end{abstract}

Additional keywords: Allee effect, pathogen containment

Karnal bunt of wheat, incited by Tilletia indica, was discovered in Arizona and California in 1996 (18). In 1997, a few fields in central Texas also were found to have the disease, and in 2001 Karnal bunt was discovered in four additional counties in Texas. In each instance, the level of disease was considered biologically insignificant (Bob Spaide, APHIS, PPQ, personal communication).

Karnal bunt can reduce wheat yields and cause a fishy, unpalatable odor and taste in wheat flour, reducing flour quality (7). Since Karnal bunt affects the international trade of commercial wheat grain and movement of germ plasm, the presence of

Corresponding author: M. R. Bonde

E-mail: mbonde@fdwsr.ars.usda.gov

Mention of trade names or commercial products in this article is solely for the purpose of providing specific information and does not imply recommendation or endorsement by the U.S. Department of Agriculture.

Accepted for publication 24 November 2003.

Publication no. D-2004-0202-02R

This article is in the public domain and not copyrightable. It may be freely reprinted with customary crediting of the source. The American Phytopathological Society, 2004. the disease can cause economic loss to wheat exporting countries (7). Available empirical and expert evidence indicates that yield and quality losses are generally minor, and most economic loss can be attributed to the quarantine status of the pathogen $(2,8)$.

Teliospores of $T$. indica are very resistant to adverse environmental conditions and have been reported to survive in contaminated soil for 2 to 5 years $(10,13-17)$. Teliospores, being the only means of surviving in soil and the main means of pathogen spread on and in wheat seed, play a vital role in the perpetuation and spread of the disease. For these reasons, they are of particular interest to plant disease regulatory officials.

After Karnal bunt was discovered in Arizona and California in 1996, questions were asked as to how long teliospores of $T$. indica survive in contaminated soil. This information was critical in making disease control decisions. To answer the question, we initiated a teliospore longevity study in April 1998 at two field sites at the University of Arizona Campus Agricultural Center, Tucson (M. R. Bonde, S. E. Nester, M. W. Olsen, and D. K. Berner, unpublished). The study demonstrated that some teliospores survived at least 48 months in irrigated and nonirrigated field plots in Tuc- son. During the first 2 years in the fields, there was a rapid reduction in teliospore viability, followed by a slower decline in viability of a smaller, more resilient teliospore population. These teliospores probably are responsible for the occasional reappearance of Karnal bunt in areas where disease has not been observed in several years.

After initiation of the project in Arizona, it became apparent that other U.S. locations, although without disease, should be tested to see how long teliospores might survive. This information could be useful in optimizing Karnal bunt disease surveys and developing Pest Risk Analyses (PRAs).

Conducting studies with $T$. indica in areas of the country without a prior history of Karnal bunt presented a major obstacle because teliospores had to be contained. A container was designed that allowed teliospores to be placed in field plots, be exposed to the environment, and yet not present a danger of escape. The main objective of the study presented here was to compare teliospore longevity at field sites selected to represent varying soil characteristics, and longevity in the same soils maintained dry in a laboratory. Data from a separate study in Arizona are included for comparison where appropriate (M. R. Bonde, S. E. Nester, M. W. Olsen, and D. K. Berner, unpublished). All research was conducted with permission from appropriate U.S. and state governments.

\section{MATERIALS AND METHODS}

Preparation of teliospore-infested soil. Soils to be infested with teliospores and placed in bags, and noninfested soil to surround the bags in containers, came from the top 20-cm layer of each field location, except Kansas. In Kansas, the soil came from a nearby wheat field. The soil was air-dried, sieved through a $2-\mathrm{mm}$ pore-size sieve to eliminate large debris, mixed, and shipped to Frederick, MD. The Cooperative Extension Service, University of Maryland, College Park, analyzed a subsample for physical and chemical characteristics. Teliospores harvested from infected seeds obtained in 1995 from Sonora, Mexico (G. Fuentes-Davila, 
CIMMYT) were suspended in Tween 20 water (1 drop Tween per $100 \mathrm{ml}$ ), passed through a $53-\mu \mathrm{m}$ pore-size nylon screen, and rinsed with water on a $20-\mu \mathrm{m}$ poresize stainless steel screen to eliminate teliospores smaller than $20 \mu \mathrm{m}$ diameter. Teliospores were suspended in water by gentle stirring, counted, divided, and concentrated. A 200- $\mu$ l aliquot of an aqueous suspension containing $2 \times 10^{4}$ teliospores was added to each bag containing $3 \mathrm{~g}$ of soil. The bags were glued shut, as described later, and allowed to cure. Identical bags of air-dried teliospore-infested soil in sealed plastic bags, and free teliospores in glass bottles, were kept in the laboratory to serve as controls.

Containers for infested soil. Bags used to contain teliospore-infested soil were made from two $5.1 \times 5.1 \mathrm{~cm}$ pieces, except where noted, of $21-\mu \mathrm{m}$ pore-size polyester mesh (Sefar America Inc., Kansas City, MO) glued together at three edges with silicone caulk (GE Silicon II Window + Door Caulk, Clear, GE Silicones of General Electric Co., Waterford, NY). The fourth side was sealed with silicone caulk after addition of the infested soil.

Containers were initially constructed in two sections, each consisting of a piece of 5-cm-diameter polyvinyl chloride (PVC) pipe $(7 \mathrm{~cm}$ long for the top section and 41 $\mathrm{cm}$ for the bottom section) covered at one end, from the inside out, with (i) a circular piece of aluminum window screen (bottom section only) to keep the soil in place, (ii) a snap-in drain grate which provides support to the column of soil on the inside as well as the screens on the outside, (iii) a circular piece of $20-\mu \mathrm{m}$ pore-size stainless steel screen (TWP, Berkeley, CA) to prevent escape of the pathogen, and (iv) a circular piece of aluminum window screen to prevent possible entry of insects and small animals (Fig. 1). These components were sandwiched into the joint between the end of the pipe and a female adapter (Fig. 1). Joints were primed and glued. (We used Oatey Purple Primer Cleaner, No. 30780; and Oatey All Purpose Cement, No. 30821.) A cleanout plug (Fig. 1) was screwed into the adapter at each end. The presence of the cleanout plugs allowed washing and transport of the containers from the containment portion of the building through a shower to the outside without getting soil inside wet. Because the containers were assembled and screens sealed into place prior to loading with soil and pathogen, later removal of the plugs in the field presented no risk of teliospore escape. PVC parts, window screen, caulk, and cement were purchased at local hardware and plumbing stores. A preliminary report of the specialized container has been presented (5) and is a modification of a similar container developed and used by Babadoost et al. (4).

The bottom section of each PVC pipe was filled to within $4.5 \mathrm{~cm}$ of the top with soil. During filling, the soil was tamped periodically, and two $5.1-\mathrm{cm}$ bags of teliospore-infested soil each were placed at 5-, $10-$, and $25-\mathrm{cm}$ depths with respect to the eventual level of the surrounding soil surface. Circular pieces of window screen and 8-mesh hardware cloth were wedged into the container to keep the soil in place during later transit (Fig. 1). The top section was glued to the bottom section. The assembled containers then were washed prior to exiting the containment facility. A total of 30 sample containers were prepared for each field site, except for Arizona. For Arizona, 12 sample containers, each holding six bags, were prepared.

Field sites. The experimental design for each field site was influenced by specific requirements set by the state in which a plot was to be situated. Each site was surrounded by a chain-link fence, except the site within the Karnal bunt area of Arizona.

The site in Arizona was located on the Creek Indian Reservation, Parker. The containers were buried in three $1.2 \times 1.2 \mathrm{~m}$ subsites located $12.2 \mathrm{~m}$ apart in a straight line on 12 January 2000. Bags of infested soil were buried outside the container pipes at the same depths as the bags within the pipes for later comparisons to determine the effects of the containers on teliospore longevity. The subsites were irrigated every 2 to 3 weeks, the frequency and amount depending on rain. One container holding three sample bags of infested soil was removed annually, selected randomly from each subsite.

The site in Kansas was $3 \times 3 \mathrm{~m}$, located within a grassy area of approximately 400 square feet with restricted access at Forbes Field, a commercial airport, in Topeka. The containers with infested field soil were buried on 31 October 1999. Soil in the bags and inside the pipes surrounding bags was a silt clay loam from a nearby wheat field.

The site in Georgia was within a former grassy pasture with a sandy loam soil. The tubes were placed in the holes on $17 \mathrm{De}$ cember 1999 in five rows, six tubes per row. Three tubes were randomly removed on each sampling date.

The site in Maryland was $7.3 \times 7.3 \mathrm{~m}$, with a clay loam soil, situated near the main USDA building (\#1301) at Fort Detrick. On 22 November 1999, 30 containers with teliospores were buried in the site in three sets of two rows of five containers. One container was randomly selected on each recovery date from each set.

At each location, just prior to removal of the container from the ground, a cleanout plug was screwed onto the top of the container. Immediately after removal from the ground, a second cleanout plug was screwed onto the bottom, thus sealing the container.

Weather data. Temperature-monitoring containers were constructed identical to the sample containers, except that prior to filling with soil, a 0.6-cm-diameter hole (for later insertion of a temperature probe) was drilled at 5,10 , and $25 \mathrm{~cm}$ below the eventual ground surface.

Soil and air temperatures were collected by Hobo weather monitoring units (Hobo H8 Pro Temp/External Temp data logger, Onset Computer Corp., Bourne, MA). At each site, Hobo probes (part no. H08-03108) were inserted into the temperaturemonitoring container through the drilled holes, and were sealed with silicone caulk.

Rainfall data were obtained from nearby weather stations at Parker, AZ; Forbes Field, Topeka, KS; Griffin, GA; and Frederick Police Barracks, Frederick, MD.

Soil moisture determination. Upon arrival of pipe containers in Frederick, the pipes were cut open, bags removed, and approximately $15-\mathrm{g}$ soil samples taken directly from below the bags at each of the three depths. The soil samples were dried at $100^{\circ} \mathrm{C}$ for at least $72 \mathrm{~h}$, and loss in weight, as a percentage of dry weight, was calculated.

Extraction of teliospores from soil samples. At each sampling date, soil from three replicate soil samples at each depth was tested for teliospore viability immediately upon arrival in Frederick. Three addi-

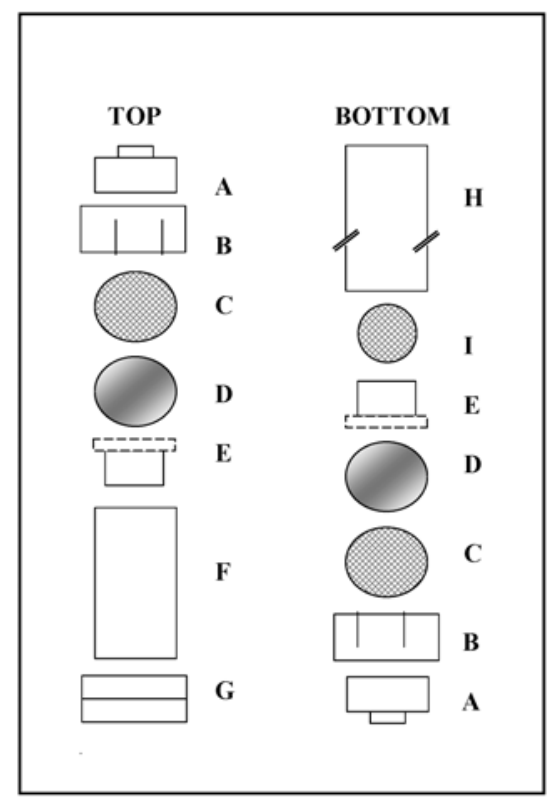

Fig. 1. Components of top and bottom sections of PVC container used to bury teliospore samples at field sites. A, 5-cm-diameter PVC cleanout plug; B, 5-cm-diameter PVC female adapter; C, 6-cm-diameter aluminum window screen; D, 6-cm-diameter $20-\mu \mathrm{m}$ pore-size stainless steel screen; E, 5-cm-diameter PVC snap-in drain; F, 7-cm-long, 5-cm-diameter PVC pipe; G, 5-cm-diameter PVC coupler; $\mathrm{H}$, 41-cm-long, 5-cm-diameter PVC pipe; I, 4.3$\mathrm{cm}$-diameter aluminum window screen. After assembly, the bottom section was filled with soil as sample bags were placed 25,10 , and 5 $\mathrm{cm}$ below the final soil surface. Hardware cloth and aluminum window screen were wedged in at the top to keep soil surface in place. Top and bottom sections were glued together. 
tional replicate bags were retained for later testing if required to determine if low germination was caused by teliospore dormancy. Bags were opened and the 3-g soil sample placed in a $250-\mathrm{ml}$ beaker along with the bag cut into pieces. The method of teliospore extraction from soil was a modification of the $80 \%$ sucrose centrifugation technique developed by Babadoost and Mathre (3). In brief, distilled water was added to a level that covered the soil, and the soil was allowed to sit overnight at room temperature. The next day, $100 \mathrm{ml}$ of distilled water and 1 drop of Tween 20 were added to the soil in each beaker and stirred for $3 \mathrm{~min}$ with a magnetic stirrer. The suspension was poured through a 53$\mu \mathrm{m}$ pore-size nylon screen, and the liquid collected. The material retained on the screen was washed with a fine stream of water until 1,000 ml (1,500 ml for Georgia and Maryland soils) was collected. The collected suspension then was poured through a $20-\mu \mathrm{m}$ pore-size nylon screen. Residue retained on the $20-\mu \mathrm{m}$ screen was washed into a 50-ml centrifuge tube and centrifuged at $1,200 \times g$ for $3 \mathrm{~min}$. The liquid was decanted, the pellet suspended in $35 \mathrm{ml}$ of $80 \%(1.6 \mathrm{M})$ sucrose, and then centrifuged at $200 \times g$ for $40 \mathrm{~s}$. The liquid was then decanted onto a $20-\mu \mathrm{m}$ screen. The residual pellet was extracted three more times. The combined residue collected on the $20-\mu \mathrm{m}$ screen was washed by means of a fine stream of water, transferred into a 15-ml centrifuge tube, brought to $14 \mathrm{ml}$ with distilled water, and termed the "soil extract".

Germination percentages of teliospores. Teliospores extracted from soil samples from the field, extracted from infested air-dried soil maintained in polyester mesh bags enclosed in plastic bags in the laboratory, or free of soil and main-

Table 1. Soil analyses for field locations in which teliospore survival study was conducted ${ }^{\text {a }}$

\begin{tabular}{lcccc}
\hline Analyses & Maryland & Georgia & Kansas & Arizona \\
\hline Soil texture & Clay loam & Sand loam & Silt clay loam & Sand loam \\
$\mathrm{pH}$ & 5.5 & 5.7 & 5.4 & 7.7 \\
$\mathrm{Mg} \mathrm{ppm}$ & 72 & 134 & 150 & 182 \\
$\mathrm{P} \mathrm{ppm}$ & 36 & 18 & 56 & 308 \\
$\mathrm{~K} \mathrm{ppm}$ & 106 & 61 & 124 & 118 \\
$\mathrm{Ca} \mathrm{ppm}$ & 660 & 316 & 1,505 & 5,660 \\
Organic $\%$ & 3.1 & 4.8 & 3.5 & 1.3 \\
$\mathrm{NO}_{3}$-N ppm & 28.8 & 2.8 & 21.6 & 18.0 \\
\hline
\end{tabular}

${ }^{\text {a }}$ Soil to be infested and placed in polyester mesh bags, and noninfested soil to be placed in the containers surrounding the bags, came from the top $20-\mathrm{cm}$ layer of the field location, except Kansas. In Kansas, soil came from the top layer of a nearby wheat field. Soils were air-dried, sieved through a 2-mm pore-size sieve to eliminate large debris, mixed, and sent to Frederick, MD. A subsample was sent to Cooperative Extension Service, University of Maryland, College Park, to be analyzed for physical and chemical characteristics.

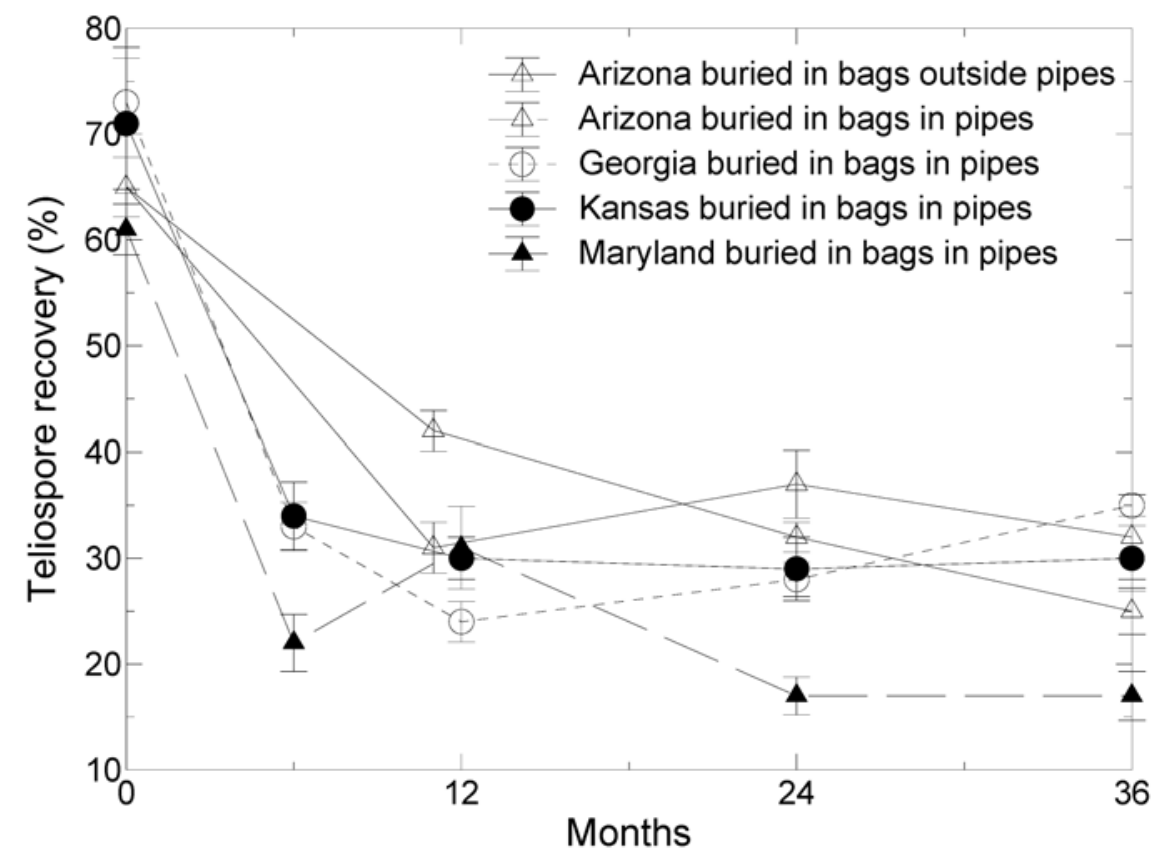

Fig. 2. Percentage of teliospores recovered, based on $2 \times 10^{3}$ teliospores added to each 3 -g bag of soil, after 0 to 36 months at field sites located in Kansas, Maryland, Georgia, and Arizona. Bags were within pipes in Kansas, Maryland, and Georgia. In Arizona, one set of bags was in pipes and one set outside pipes.

tained in glass bottles in the laboratory were incubated overnight in $14 \mathrm{ml}$ of distilled water at $20^{\circ} \mathrm{C}$, centrifuged at $1,200 \times$ $g$, and the supernatant discarded. The pellet was resuspended in $14 \mathrm{ml}$ of AEW (6) and gently rocked for $30 \mathrm{~min}$ on a Speci Mix (Barnstead/Thermolyne, Dubuque, IA) to surface sterilize teliospores. The suspension was centrifuged at $1,200 \times g$ for $3 \mathrm{~min}$, supernatant removed, and pellet resuspended in $14 \mathrm{ml}$ of sterile distilled water. The resulting suspension was centrifuged at $1,200 \times g$ for $3 \mathrm{~min}$, and supernatant discarded. The final pellet was resuspended in $4 \mathrm{ml}$ of sterile $0.1 \%$ water agar (to help keep teliospores in suspension), and the number of teliospores per $\mathrm{ml}$ was enumerated by means of a Howard Mold Counting Chamber (Hausser Scientific Partnership, Horsham, PA). An aliquot estimated to contain 100 teliospores was placed on $2 \%$ water agar containing 100 $\mathrm{mg}$ of streptomycin sulfate and ampicillin sodium salt per liter in each of six petri dishes. The volume of liquid per dish was brought to $200 \mu \mathrm{l}$ and spread over the surface of the solid medium. Dishes were incubated at $20^{\circ} \mathrm{C}, 12-\mathrm{h}$ day length (coolwhite fluorescent light), and teliospores examined at $\times 10$ to $\times 100$ magnification after 11 days to determine germination percentages.

Determination of total number of viable teliospores (TNVT). TNVT for each soil sample was determined as described elsewhere (M. R. Bonde, S. E. Nester, M. W. Olsen, and D. K. Berner, unpublished). In brief, following extraction of teliospores from the respective soil samples, each residual soil pellet (containing teliospores not able to be extracted from the soil sample) was suspended in $35 \mathrm{ml}$ of $0.1 \%$ agar, and a $1-\mathrm{ml}$ aliquot was transferred to a 20 $\mu \mathrm{m}$ pore-size screen, rinsed, and all material retained by the $20-\mu \mathrm{m}$ screen placed in a $15-\mathrm{ml}$ centrifuge tube. This material was treated with AEW, suspended in $1.2 \mathrm{ml}$ of $0.1 \%$ sterile water agar, and divided equally onto six petri dishes containing $2 \%$ water agar with antibiotics as described above. The dishes were incubated as above and examined microscopically after 11 days to determine numbers of $T$. indica colonies. The total number of colonies on the six dishes was multiplied by 35 , since $1 / 35$ th of the pellet had been spread on the growth medium, to estimate the number of viable teliospores remaining in the soil pellet. The number of viable teliospores in the pellet was added to the number in the soil extract to provide an estimate of the TNVT originally present in a soil sample.

Dormancy. Teliospores in the Kansas soil samples were tested to determine if dormancy was responsible for the low teliospore germination percentages. Germination percentages of extracted teliospores and TNVT were determined for 12 month soil samples at the time of recovery from the field site and for soil samples 
held 5 months in the lab. Data from the two test dates were compared to determine whether TNVT had increased. An increase would indicate that some of the teliospores had been dormant.

Statistical analyses. All statistical analyses were done using SAS (Statistical Analysis System, SAS Institute, Cary, NC). TNVT data were subjected to analysis of variance with the GLM procedure to test within states, significance of laboratory and field sites, soil depths, and the interaction among these effects. The model error term was used to test all effects.

To compare rates of decline of germination of teliospores extracted from soils in the laboratory, germination percentages were transformed by the natural logarithm, and these data were used in analysis of covariance to statistically compare slopes. Sampling times within states were used as the covariates in the analysis of differences between states. Regression analysis of these data within states was used to generate coefficients of determination.

Data on TNVT for laboratory and field samples in each state were analyzed by nonlinear regression using the NLIN procedure with TNVT as the dependent variable and sampling time as the independent variable. The regression analyses were done using the Marquardt method and starting parameter values of $b 1=1,200$ and $b 2=-0.01$ for the equation: $y=$ $b 1^{*} e^{(b 2 * x)}$. Using the MEANS procedure, mean values for TNVT and the standard errors of the means were generated for laboratory and field samples in each state at each sampling time. Regression lines of the equations generated by the nonlinear regression analyses were plotted along with the means and standard errors of the means for laboratory and field samples in each state.

To compare rates of decline of TNVT in air-dried soils from different states maintained in the laboratory, TNVT data for each sampling time were transformed by the natural logarithm, and these data were subjected to analysis of covariance with the GLM procedure. The natural logarithm of TNVT within soil from each state was the dependent variable, and sampling times within states were covariates. Linear regression equations for transformed TNVT versus sampling time were formed from the latter analysis and compared with equations produced by linear regression and the REG procedure, which also produced $R^{2}$ estimates. Slope estimates of the regression equations for each state were statistically compared using single degreeof-freedom contrasts in the analysis of covariance.

Teliospore appearance. During the course of the 36-month study, representative teliospores were extracted from soil samples by $80 \%$ sucrose centrifugation as described above and photographed by means of an Optronics 1-CCD digital video camera (Optronics, Goleta, CA) on an Olympus BX 41 compound microscope (Olympus America Inc.). Photographs for each depth within and among field sites, and control soils and pure teliospores maintained in the laboratory, were later compared to determine changes in teliospore appearance during the 36-month period.

\section{RESULTS}

Soil analyses. Results of soil analyses are presented in Table 1. The Arizona soil had a $\mathrm{pH}$ of 7.7 and was comparatively low in organic matter. The $\mathrm{pH}$ values of the other soils were 5.4 to 5.7 .

Weather. At each location, the mean air and mean soil temperatures were nearly identical, but daily temperature fluctuations were greatest in air and decreased with soil depth. Mean soil temperatures were $12.8,12.7,18.6$, and $23.6^{\circ} \mathrm{C}$ in Maryland, Kansas, Georgia, and Arizona, respectively. Maximum soil temperatures were $29.1,34.8,38.8$, and $45.4^{\circ} \mathrm{C}$, respectively, for the four locations. Minimum

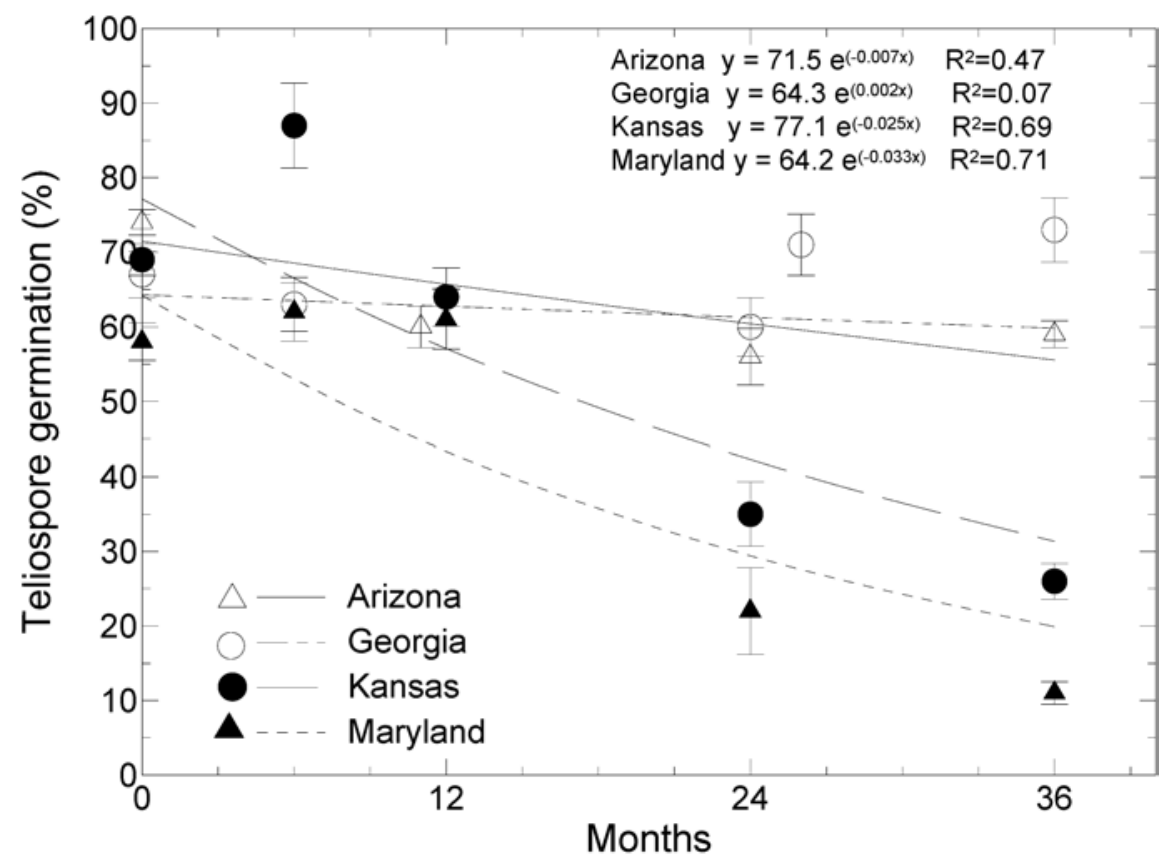

Fig. 3. Nonlinear regressions of percent teliospore germination over time for teliospores maintained in the laboratory in soils from Kansas, Maryland, Georgia, and Arizona.

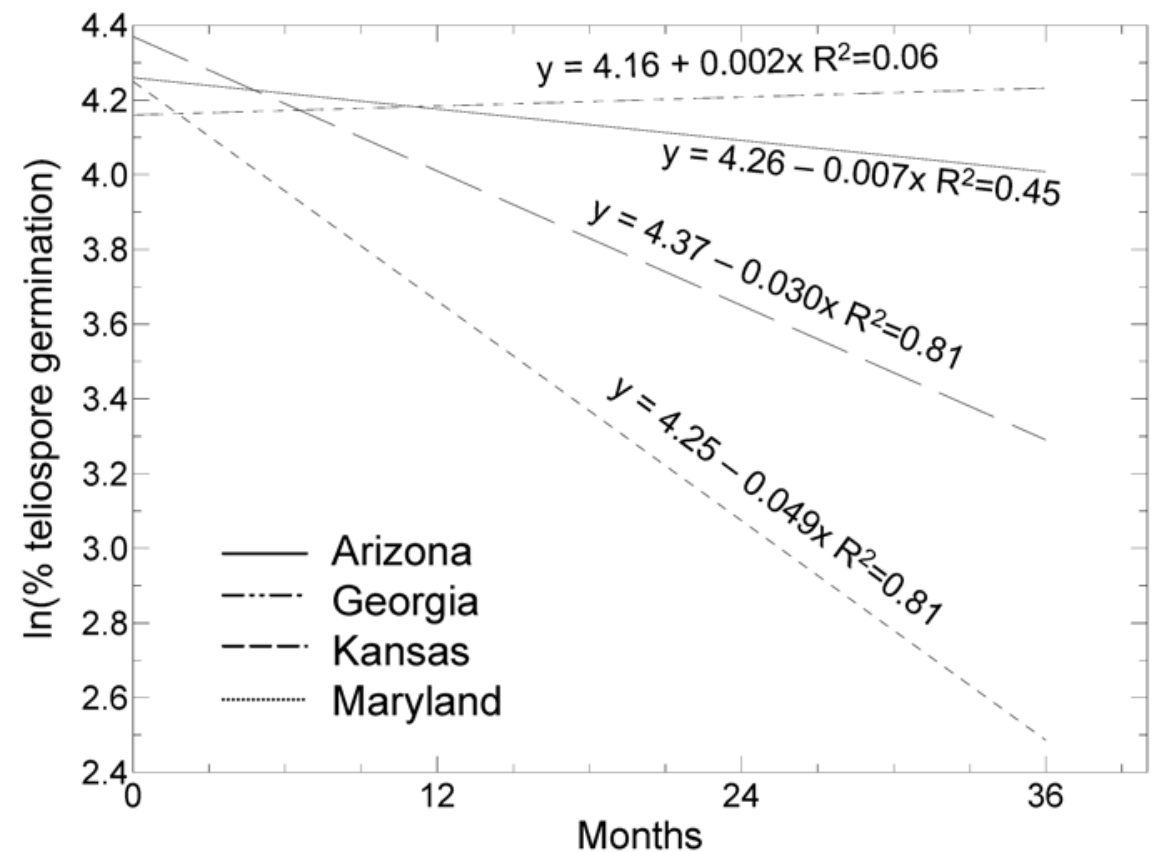

Fig. 4. Linear regressions of $\ln$ (percent teliospore germination) over time for teliospore-infested soil maintained dry at room temperature in the laboratory. 
temperatures were $-1.5,-0.6,0.3$, and $4.6^{\circ} \mathrm{C}$, for Maryland, Kansas, Georgia, and Arizona, respectively. Maryland experienced freezing temperatures at 5- and 10$\mathrm{cm}$ depths for 1886 and $931 \mathrm{~h}$, respectively, and Kansas experienced freezing temperatures at 5 and $10 \mathrm{~cm}$ for 1011 and $112 \mathrm{~h}$, respectively. Soil did not freeze in Georgia or Arizona.

Cumulative rainfalls for 3 years were 294, 247, 288, and $23 \mathrm{~cm}$ for Maryland, Kansas, Georgia, and Arizona, respectively. The Arizona site was flood irrigated approximately every 2 to 3 weeks during the growing season, the amount depending on rainfall. The average percentages for soil moisture inside the pipes were 33.8 , $36.8,32.9$, and $16.3 \%$ for Maryland, Kansas, Georgia, and Arizona, respectively, based on average soil moisture determinations for samples collected over 3 years. In Maryland, soil moisture outside containers averaged $28.1 \%$, approximately $5.7 \%$ lower than inside containers. Outside soil moisture measurements were not obtained at the other sites.

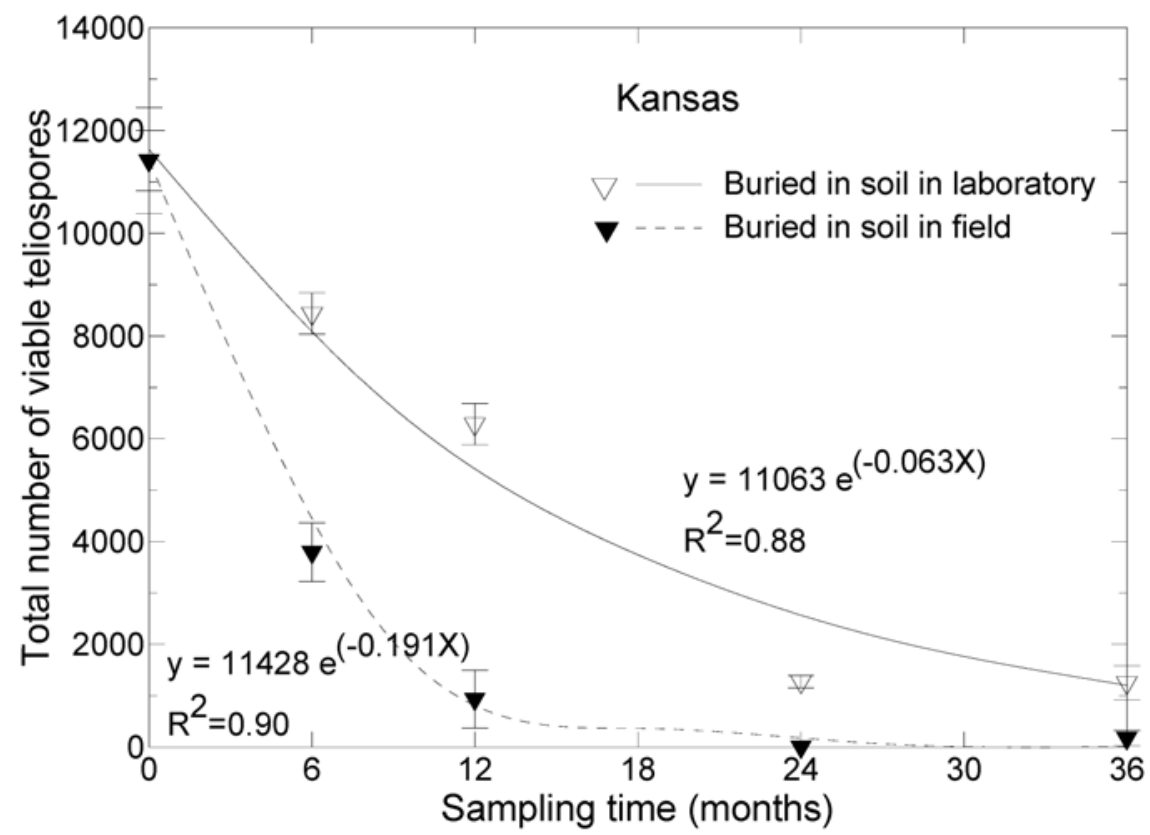

Fig. 5. Nonlinear regressions of total number of viable teliospores in soil in bags in pipes at a nonirrigated site in Kansas, and in the same soil in a laboratory, over five sampling periods. Linear transformations of the regression equations are: $\ln \left(y_{\text {laboratory }}\right)=9.32-0.063 x ; \ln \left(y_{\text {field }}\right)=9.34-0.191 x$.

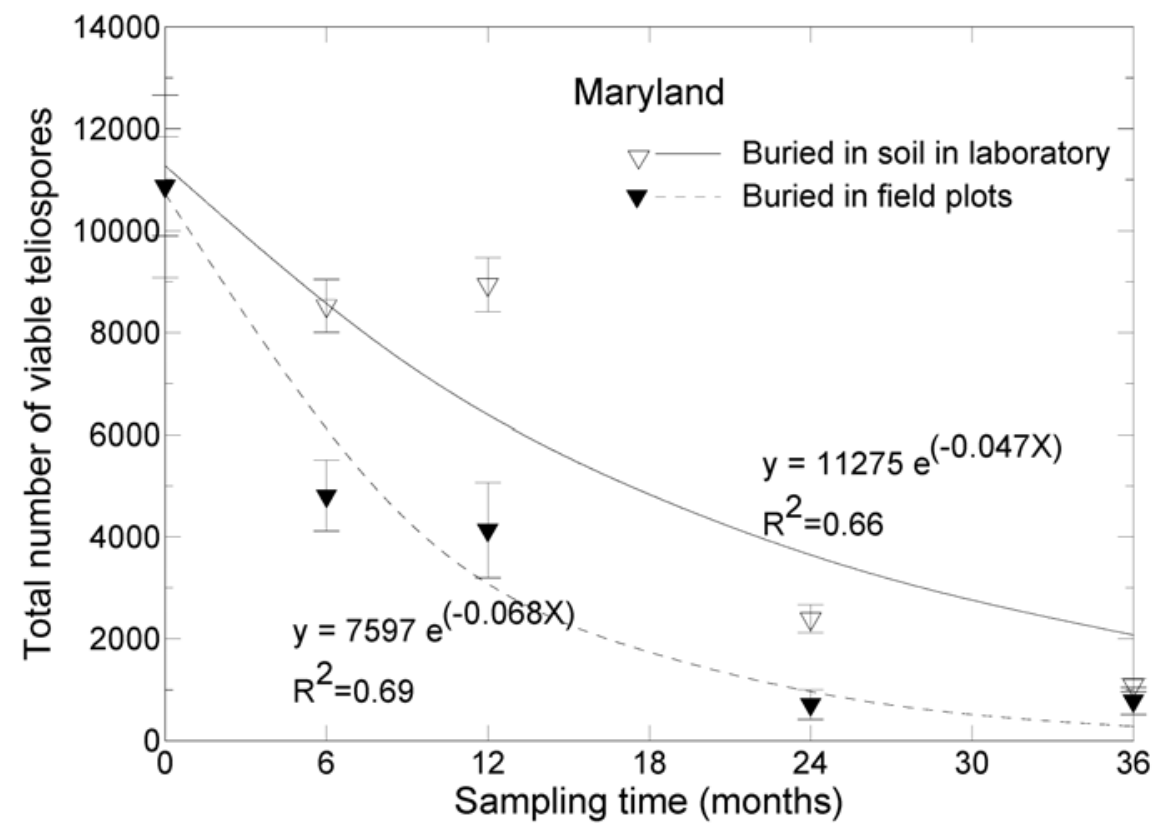

Fig. 6. Nonlinear regressions of total number of viable teliospores in soil in bags in pipes at a nonirrigated site in Maryland, and in the same soil in the laboratory, over five sampling periods. Linear transformations of the regression equations are: $\ln \left(y_{\text {laboratory }}\right)=9.33-0.0470 x ; \ln \left(y_{\text {field }}\right)=8.94-0.0681 x$.

Extraction efficiency and germinability of teliospores from soil. A marked decrease in the percentage of extractable teliospores from soil by the sucrose centrifugation was observed at 6 months, the earliest sampling time (Fig. 2). By 36 months, germination in field soil samples had declined from 66.8 to $27.0 \%$ for the Georgia soil, 57.7 to $11.1 \%$ for Maryland soil, 68.8 to $2.2 \%$ for Kansas soil, 73.7 to $7.5 \%$ for Arizona soil in pipes, and 73.7 to $12.8 \%$ for Arizona soil outside pipes. Percent germination for the laboratory control teliospores in bottles without soil decreased from $59.5 \%$ at the beginning of the experiment to $56.1 \%$ by 36 months. Nonlinear regressions of percent teliospore germination over time for teliospores maintained in the laboratory in soils from the four states are presented in Figure 3, and linear regressions of the natural logarithm of germination percentages in Figure 4. The slope of the line for each state was significantly different from that of each of the other states (Fig. 4).

Total number of viable teliospores (TNVT) in soil. Nonlinear regressions of TNVT for soil samples recovered from the field plots after 0 to 36 months and for identical soil samples maintained in the laboratory are presented in Figures 5 through 8 . TNVT decreased more rapidly in soil in containers in the field than in the same soil maintained dry in the laboratory. In the laboratory, the greatest rate of viability decline was for teliospores in the Kansas soil (Fig. 9), which had a significantly steeper slope than all other soils except from Maryland (Fig. 10). The decline in viability for the Maryland soil in the laboratory was significantly steeper than for soils from Arizona and Georgia. The rate of decline for the Parker, AZ soil was similar to that of soil from Tucson, reported from a study described elsewhere (included in Figs. 9 and 10). The decrease in teliospore viability was initially greater in bags in pipes than in bags outside pipes (Fig. 8).

Teliospore dormancy. Average TNVT for 12-month Kansas soil samples plated immediately upon arrival in Frederick and identical soil samples from the field maintained for 5 months in the laboratory before plating were each approximately $1 \times$ $10^{3}$, indicating no dormancy effect. TNVTs for control Kansas soil maintained 12 months in the laboratory and plated immediately, and the same soil plated 5 months later, averaged 6,286 and 2,681, respectively.

Physical appearance of teliospores recovered from soil. Microscopic examination of teliospores indicated that the sheath surrounding each individual teliospore was absent by 6 months. As time progressed, the outer walls of teliospores began to appear ragged and sometimes lighter in color, the latter probably a result of melanin loss (Fig. 11). There was no apparent 
change for teliospores maintained dry in soil in the laboratory (Fig. 11).

\section{DISCUSSION}

The rate of decline of TNVT over 48 months at two field sites in Tucson is reported elsewhere (M. R. Bonde, S. E. Nester, M. W. Olsen, and D. K. Berner, unpublished). At both sites, initially teliospore viability declined rapidly, but after 2 years a smaller population of resilient teliospores lost viability at a slower rate. These resilient teliospores probably are responsible for the sporadic reappearance of low levels of disease in Arizona and Texas (Bob Spaide, APHIS, PPQ, personal communication). The Southwest is not typical of most wheat-producing regions of the country, and teliospore longevity there might not be representative.

Because Parker was within the Karnal bunt-quarantined area of the United States, it provided the opportunity to compare teliospore longevity inside and outside containment pipes. Since teliospores at Parker initially lost viability more rapidly inside than outside pipes, we concluded that the pipes enclosing the bags of teliospores affected longevity. For this reason, we place major weight for drawing conclusions from this study on teliospore-infested field soils maintained in the laboratory, even though laboratory conditions were not natural.

Regression analyses of natural log TNVT over time allowed a comparison of rates of viability decline (Fig. 10). The rate of decline in the laboratory was significantly greater in Kansas and Maryland soils than in soil from Georgia or Parker, AZ (Fig. 10). The rate of decline in Parker soil was nearly identical to that of a soil from Tucson (Fig. 10). Because the number of teliospores originally added to the soil from Tucson was half that of the other soils, the regression line was correspondingly lower (Fig. 10). The factor(s) inherent with the Kansas and Maryland soils responsible for the steeper declines in teliospore viability has yet to be determined. The steeper decline in Kansas and Maryland soils maintained in the laboratory (Fig. 10) indicated teliospore longevity was influenced by the soil itself, irrespective of weather or climate.

The comparable survival of teliospores in the Georgia soil with that in the Arizona soils might be expected since a very close relative to $T$. indica is known to survive in Georgia (9).

The experimental design for this study differed from our earlier study, in which pipe containers were not used, because of a different level of required containment assurance. Furthermore, because of a limited quantity of teliospores in the teliospore lot used for the first experiment, we had to use a different lot for the second experiment. However, the two lots behaved similarly. Because teliospore-infested soils maintained in the laboratory in both studies had been treated identically, even maintained side-by-side on the same laboratory shelf, the results can be compared directly.

Based on regression analyses, at 36 months in Arizona, TNVT had declined $15 \%$ more inside pipe containers than outside containers (Fig. 8), possibly due to soil in containers remaining damp for long periods. However, we note that the average moisture level for the Arizona soil in containers was considerably lower than that of soil within containers at the other locations. Yet viability declined nearly as rapidly, suggesting that soil moisture may not be the only factor contributing to rapid decrease in viability in containers. Although it would be desirable to conduct teliospore longevity studies in the field without the use of containers, the requirement for stringent containment precluded these studies.

The major changes in teliospore appearance in the field, and no apparent change

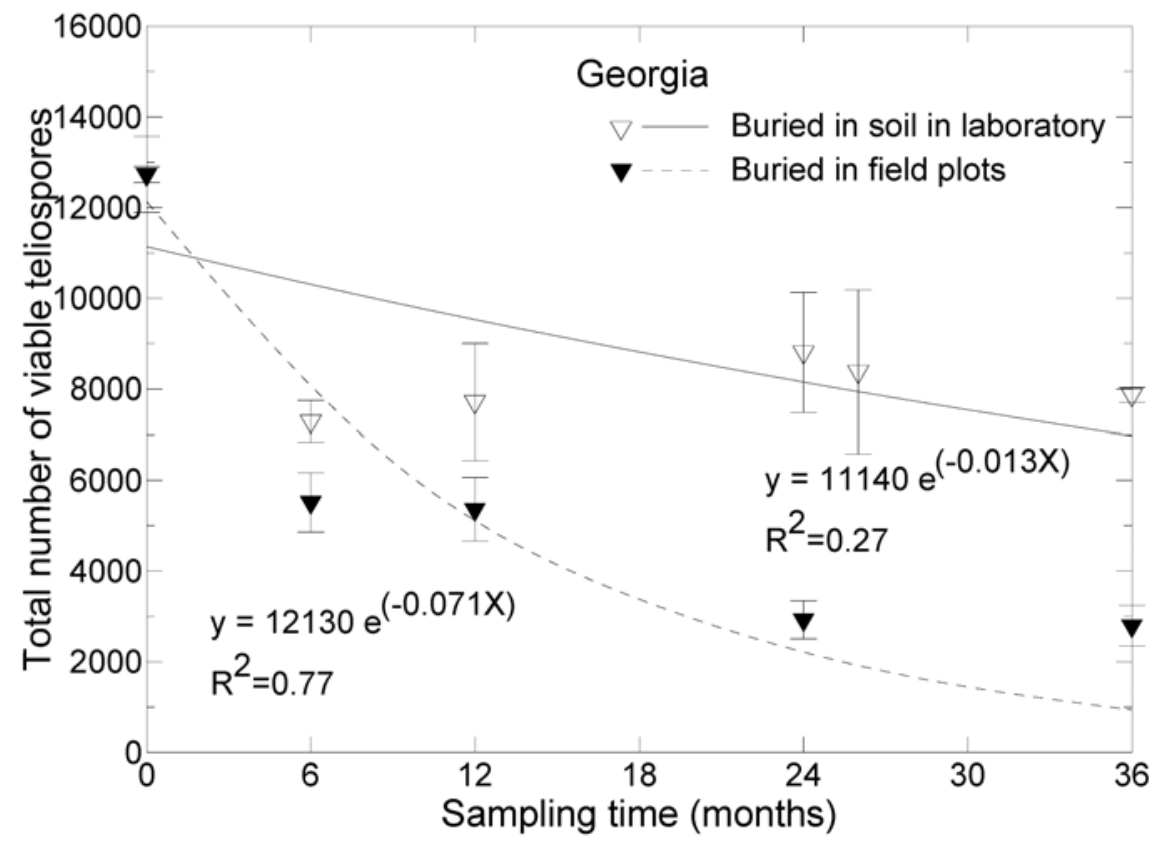

Fig. 7. Nonlinear regressions of total number of viable teliospores in soil in bags in pipes at a nonirrigated site in Georgia, and in the same soil in the laboratory, over five sampling periods. Linear transformations of the regression equations are: $\ln \left(y_{\text {laboratory }}\right)=9.32-0.013 x ; \ln \left(y_{\text {field }}\right)=9.40-0.071 x$.

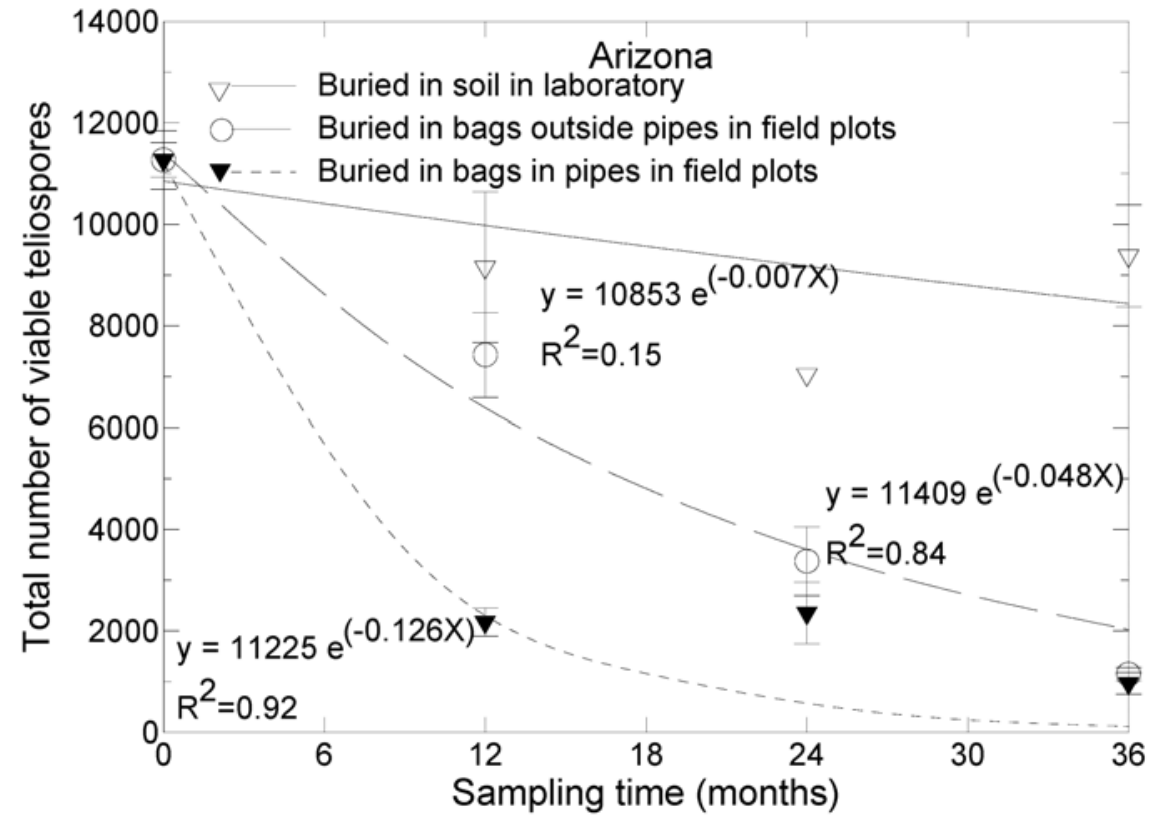

Fig. 8. Nonlinear regressions of total number of viable teliospores in bags inside pipes, and in bags outside pipes, at an irrigated site in Arizona, and in the same soil in the laboratory, over four sampling periods. Linear transformations of the regression equations are: $\ln \left(y_{\text {laboratory }}\right)=9.29-0.007 x ; \ln \left(y_{\text {bags }}\right)$ $=9.34-0.048 x ; \ln \left(y_{\text {pipes }}\right)=9.33-0.126 x$. 
in the laboratory (Fig. 11), concomitant with a rapid loss of teliospore viability in both field and laboratory with Kansas and Maryland soils, showed viability loss was not correlated with changes in teliospore appearance.

Soil $\mathrm{pH}$ probably was not a factor affecting teliospore longevity in our study because the pHs of the Georgia, Kansas, and Maryland soils were all nearly the same (Table 1), yet teliospore longevity declined significantly faster in the laboratory in the later two soils (Fig. 10). The only soil characteristics directly associated with teliospore longevity were the soil nitrate levels and soil texture (Table 1). Georgia and Arizona soils had lower ppm $\mathrm{NO}_{3}-\mathrm{N}$ and higher sand contents than soils from Maryland and Kansas, in which teliospores lost viability significantly faster. An indirect relationship existed between soil temperatures experienced prior to collection of soil at the beginning of the study and longevity in the laboratory. The significantly

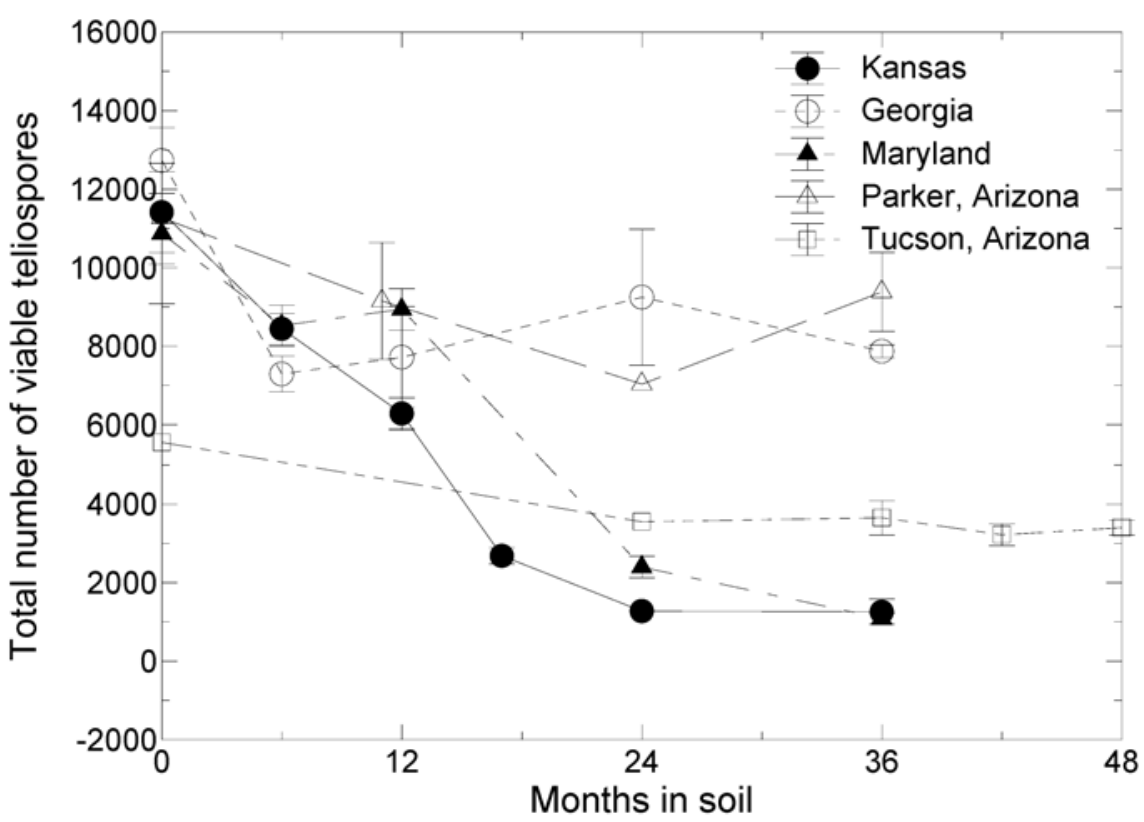

Fig. 9. Total number of viable teliospores (TNVT) in 3-g soil samples maintained in the laboratory for 0 to 36 months. Data for Tucson, AZ are from a separate study (M. R. Bonde, S. E. Nester, M. W. Olsen, and D. K. Berner, unpublished).

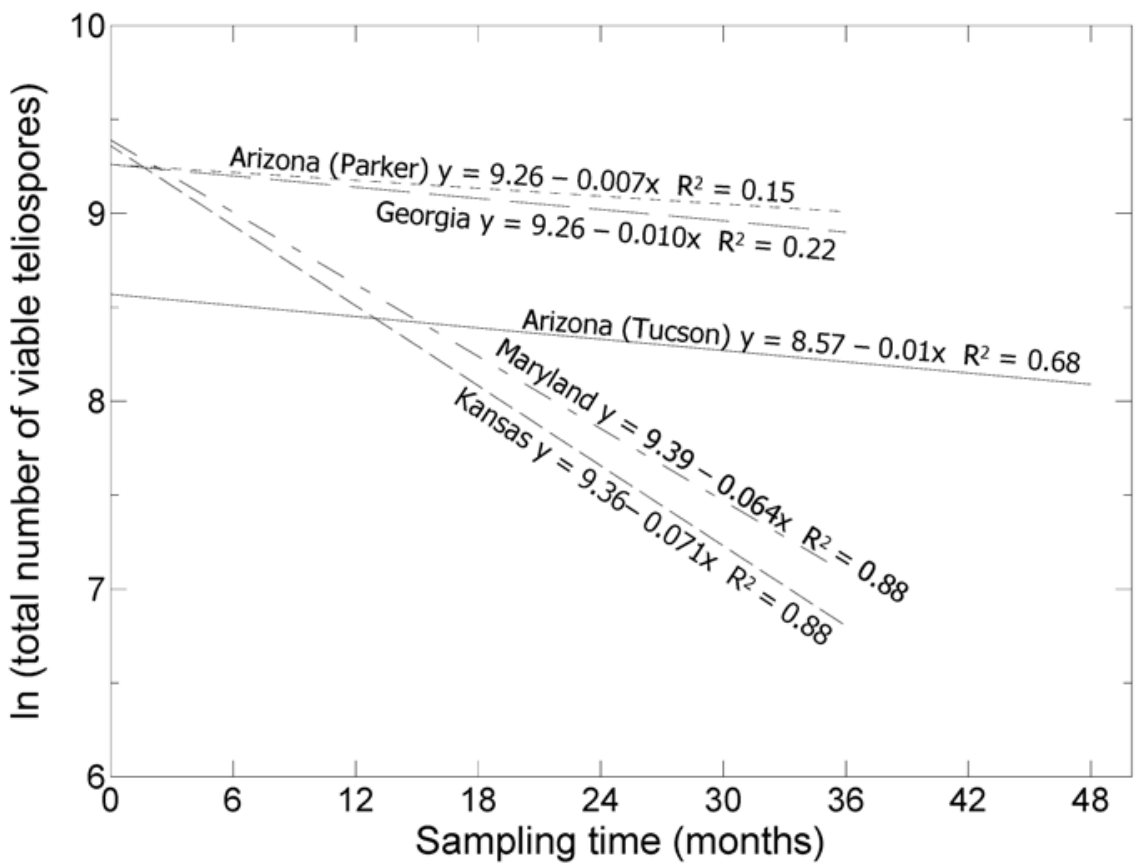

Fig. 10. Linear regressions of $\ln$ (total number of viable teliospores) over time for teliospore-infested soils from Kansas, Maryland, Georgia, and Arizona maintained dry at room temperature in the laboratory. higher temperatures experienced for the Arizona and Georgia soils conceivably altered microbial populations.

We drew conclusions mainly from decline of TNVT in artificially infested field soils. TNVT represents the entire teliospore population and therefore is more meaningful than a measurement based solely on extracted teliospores. The incomplete, and sometimes poor, teliospore extraction from soils leaves doubt as to the validity of the data. Increasing the sucrose concentration from the standard $80 \%$ up to $90 \%$ failed to improve extraction (M. R. Bonde and S. E. Nester, data not presented), and other techniques, such as the glycerol extraction technique of Singh et al. (17), produced extracts in which it was difficult to recognize teliospores among the debris (M. R. Bonde and S. E. Nester, data not presented). As a result, ungerminated teliospores could not be easily differentiated from soil particles of similar size, which introduced significant error into germination percentages. In spite of the inherent problem with interpretation of germination percentages of extracted teliospores, in our study the decline in teliospore germinability approximately paralleled the decline in TNVT (Figs. 3 to10), but this was not always the situation (M. R. Bonde, S. E. Nester, M. W. Olsen, and D. K. Berner, unpublished).

Babadoost et al. (4) also observed a rapid decline in both numbers of teliospores extracted and germination percentages in container pipes in the field in Montana. Contrary to our Kansas and Maryland soils, in the laboratory germination decreased very little in 32 months.

The TNVT method provided a total number of viable teliospores in a soil, and when compared to TNVT at several points in time, allowed an accurate estimate of rate of decline of viable teliospores. Nonviable teliospores were not considered. The TNVT method was simple to perform and was not affected by a variable extraction efficiency. Furthermore, nongerminated teliospores did not have to be discerned from soil particles of similar size, which can be a major problem and can introduce considerable error into results.

In each soil, the proportion of viable teliospores in the pellet initially was small, but as the numbers of viable teliospores decreased, the proportion of viable teliospores remaining in the residual pellet increased. By excluding these teliospores, it is possible to underestimate the longevity of $T$. indica in soil.

Numbers of viable teliospores in soil are relevant when determining probability that disease will occur and the amount of disease. Garrett and Bowden (12) recently described the "Allee" effect and how it might limit population growth of $T$. indica. Many organisms require mating between different sexes, or mating types, for reproduction, and at low population densities 
the inability to find a compatible mate becomes a major limiting factor. In some instances extinction occurs (12). This limitation does not occur with the other bunt diseases of wheat, such as dwarf bunt, in which the pathogen, $T$. controversa, mates on the basidium prior to liberation of sporidia (12). For that reason, the disease inciting potential of $T$. indica can be expected to be less.

Babadoost (2) believed that $T$. indica teliospores may be frequently introduced into new areas, but the pathogen fails to become established. The Allee effect could explain why $T$. indica is difficult to establish. Either the pathogen does not find a suitable host, or minimal infection results and the pathogen population cannot be sustained. This situation would occur whenever the rate of reproduction is less than the rate of decline of viable teliospores. As suggested by Garrett and Bowden (12), the frequency at which environmental conditions are conducive for initiation of infection could play a vital role in the likelihood of establishment. For example, whereas suitable conditions every 3 years might allow survival, conducive conditions every 4 years might result in extinction (12). The preponderance of evidence suggests that in most localized areas of the United States, the environment seldom is conducive for infection (1). It might explain why Karnal bunt continues to be a minor disease wherever it has occurred in the world $(7,8,11)$.

Our study demonstrated that teliospores of $T$. indica survived for different durations in different air-dried soils. The rapid demise of teliospores in the Kansas and Maryland soils in the laboratory was not associated with any obvious changes in appearance of the teliospores. Future studies should compare longevity in a wide range of soils under standard temperature and available moisture levels. Research should be conducted to determine the cause of the higher rates of decline in teliospore viability in some soils, and how this may limit disease establishment. The methodology used should measure changes in teliospore viability within the whole teliospore population and be sensitive enough to follow low teliospore populations. Information obtained will be crucial in evaluating the potential for spread and establishment of Karnal bunt.

\section{ACKNOWLEDGMENTS}

We thank Joseph Smilanick, Blair Goates, Robert Spaide, and Douglas Luster for many helpful suggestions throughout the study; Guillermo Fuentes-Davila for providing the source of teliospores from Sonora, Mexico; Edward Alexander for providing the electrolysis apparatus to generate AEW and guidance in its use; and Megan Reeher and the late Lillian Zuback for excellent technical assistance during critical periods in the study.

\section{LITERATURE CITED}

1. Anonymous. 2001. An epidemiological approach to assessing the risk of establishment of Karnal bunt, Tilletia indica Mitra, in North America. North American Plant Protection Organization (NAPPO)

2. Babadoost, M. 2000. Comments on the zerotolerance quarantine of Karnal bunt of wheat. Plant Dis. 84:711-712.

3. Babadoost, M., and Mathre, D. E. 1998. A method for extraction and enumeration of teliospores of Tilletia indica, T. controversa, and $T$. barclayana in soil. Plant Dis. 82:1357-1361.

\section{FIELD SAMPLES}
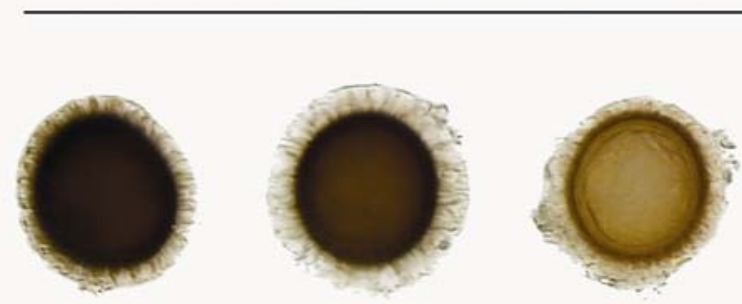

\section{Kansas}
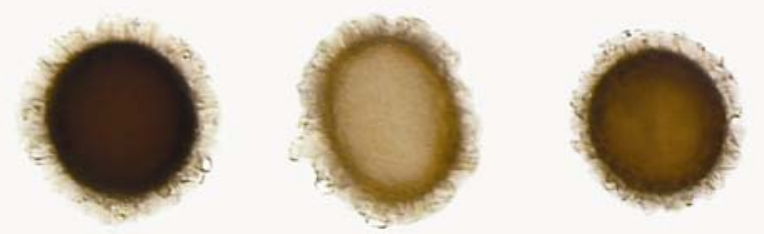

Maryland
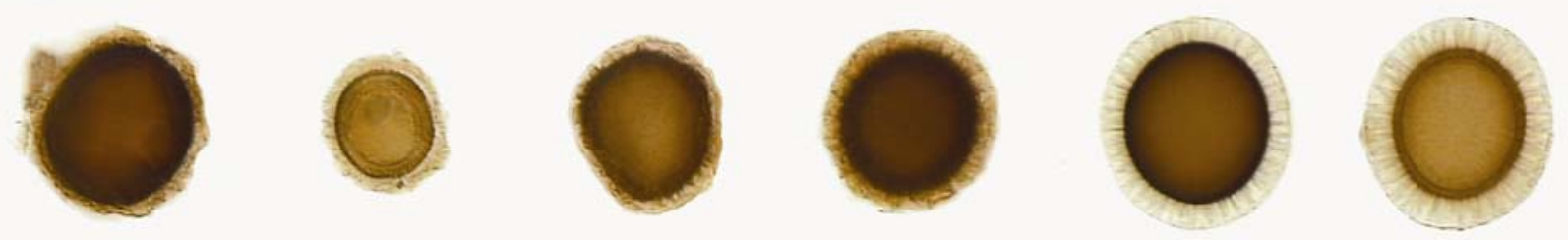

Georgia
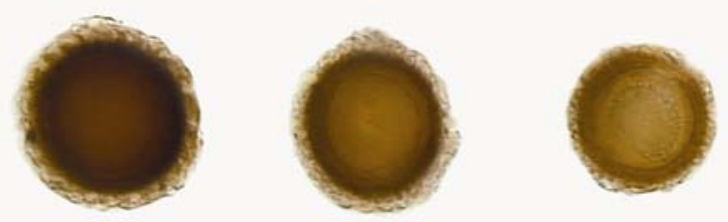

Arizona
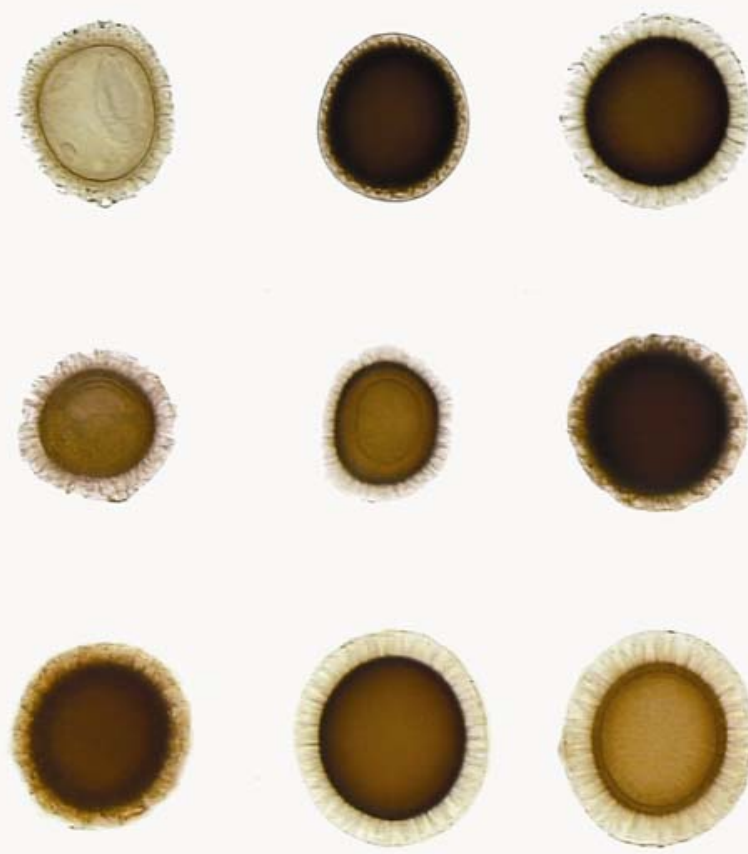

\section{LAB CONTROL}
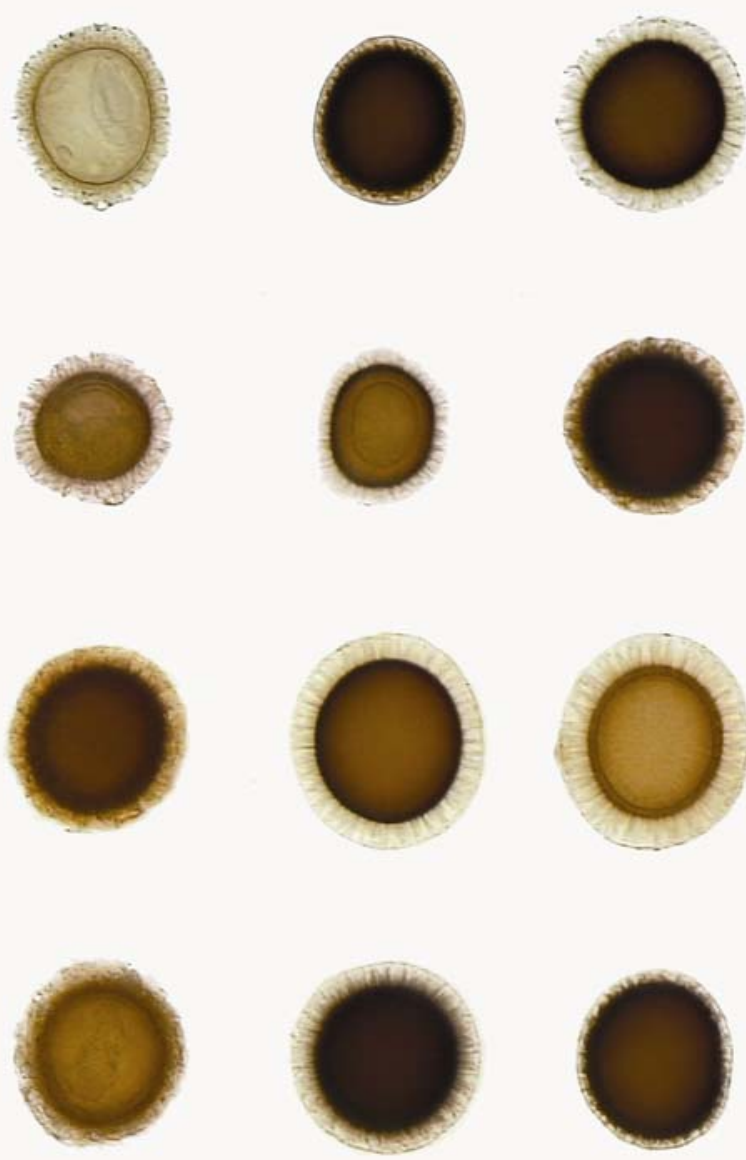

$35 \mu \mathrm{m}$

Fig. 11. Representative teliospores extracted by $80 \%$ sucrose centrifugation from bags of infested soil recovered from field sites and the same soils maintained dry at room temperature in the laboratory. 
4. Babadoost, M., Mathre, D. E., Johnston, R. H., and Bonde, M. R. 2004. Survival of teliospores of Tilletia indica in soil. Plant Dis. 88:56-62.

5. Bonde, M. R., Nester, S. E., Peterson, G. L., and Babadoost, M. 2000. Teliospore escapeproof containers for Karnal bunt field studies. (Abstr.) Phytopathology 90:S131.

6. Bonde, M. R., Nester, S. E., Schaad, N. W., Frederick, R. D., and Luster, D. G. 2003. Improved detection of Tilletia indica teliospores in seed or soil by elimination of contaminating microorganisms with acidic electrolyzed water. Plant Dis. 87:712-718.

7. Bonde, M. R., Peterson, G. L., Schaad, N. W., and Smilanick, J. L. 1997. Karnal bunt of wheat. Plant Dis. 81:1370-1377.

8. Butler, L. 1990. Karnal bunt, quarantine and the international shipment of CIMMYT wheat seed. Proc. Bien. Workshop Smut Fungi, 7th.
9. Castlebury, L. A., and Carris, L. M. 1999. Tilletia walkerii, a new species on Lolium multiflorum and L. perenne. Mycologia 91:121-131.

10. Chib, H. S., Kalha, C. S., Gupta, B. R., Tikoo, M. L., and Gupta, R. S. 1990. Studies on the longevity of Neovossia indica - The incitant of Karnal bunt of wheat in soil. Plant Dis. Res. 5(Special):17-18.

11. Fuentes-Davila, G. 1998. Karnal bunt of wheat. Pages 69-81 in: Proc. Bunts Smuts Wheat, Int. Sympos. August 17-20, 1997.

12. Garrett, K. A., and Bowden, R. L. 2002. An Allee effect reduces the invasive potential of Tilletia indica. Phytopathology 92:1152-1159.

13. Krishna, A., and Singh, R. V. 1983. Longevity of teliospores of Neovossia indica causing Karnal bunt of wheat. Indian J. Mycol. Plant Pathol. 13:97-98.

14. Mathur, S. B., and Cunfer, B. M. 1993. Karnal bunt. Pages 31-43 in: Seed-borne Diseases and Seed Health Testing of Wheat. Jordbrugsforlaget, Frederiksberg, Denmark.

15. Munjal, R. L. 1970. Studies on Karnal bunt of wheat. Ph.D. thesis. Punjab University, Chandigarh.

16. Rattan, G. S., and Aujla, S. S. 1990. Survival of Karnal bunt (Neovossia indica) teliospores in different types of soil at different depths. Indian J. Agric. Sci. 60:616-618.

17. Singh, D. V., Siddiqui, K. A., Aggarwal, R., Srivastava, K. D., Maurya, A. K., and Arora, P. 1990. Extraction of teliospores of Neovossia indica from soil mixed with the teliospores. Indian Phytopathol. 43:500-503.

18. Ykema, R. E., Floyd, J. P., Palm, M. E., and Peterson, G. L. 1996. First report of Karnal bunt of wheat in the United States. Plant Dis. 80:1207. 